\title{
Reflexões sobre o estágio na educação superior e sua particularidade no Serviço Social
}

\author{
Maisa Miralva da Silva \\ Pontifícia Universidade Católica de Goiás (PUC-GO)
}

\author{
Eleusa Bilemjian Ribeiro \\ Pontifícia Universidade Católica de Goiás (PUC-GO)
}

\section{Reflexões sobre o estágio na educação superior e sua particularidade no Serviço Social}

Resumo: O presente artigo traz uma discussão sobre o estágio, enfocando-o como componente do processo de formação nos cursos de nível superior, conforme mostra a história da educação brasileira. Objetivo é apresentar algumas reflexões sobre o curso de Serviço Social e o estágio como aproximação e introdução dos estudantes ao exercício profissional, preparando-os para a vivência de aspectos éticopolíticos, teórico-metodológicos e técnico-operacionais da profissão. O estágio compõe uma diversidade metodológica que tem traçado os rumos da sua supervisão, de seus objetivos e de suas concepções. Alguns desses elementos caracterizam o estágio como atividade complementar, periférica, exógena aos propósitos do processo de formação o que, em alguns casos, fortalece a dicotomia teoria-prática e o conservadorismo na profissão.

Palavras-chave: Estágio. Educação superior. Serviço Social.

\section{Reflections on Internships in Higher Education and their Particularity in Social Work}

Abstract: This article discusses internships, focusing on them as components of the educational process in higher education programs, as shown by the history of Brazilian education. The objective is to present some reflections on the trajectory of social service and internships as a way to approximate and introduce students to professional practice, preparing them to experience ethical-political, theoretical-methodological and technical-operational aspects of the profession. Internships have encompassed a methodological diversity that trace the direction of supervision, and its objectives and concepts. Some of these elements characterize internships as a complementary, peripheral activity, which is exogenous to the proposals of the educational process that, in some cases, strengthens the dichotomy between theory and practice and a conservative approach to the profession.

Keywords: Internship. Higher education. Social Work. 


\section{Reconhecimento legal do estágio na educação superior}

O primeiro instrumento específico que, em âmbito nacional, regulamentou o estágio foi a Portaria n. 1.002 (BRASIL, 1967). Institui nas empresas e não nas escolas/universidades, a figura do estagiário, ao estabelecer: "Fica instituída nas empresas a categoria de estagiário a ser integrada por alunos oriundos das Faculdades ou Escolas Técnicas de nível colegial" (BRASIL, 1967, Art. 1º). Em seus considerandos, o documento apresenta as condições necessárias, à época, para um maior "entrosamento escola-empresa", isto é, buscava-se a "formação e o [...] aperfeiçoamento técnico-profissional" dos estudantes, para que se alcançasse o "desenvolvimento, [...] nos moldes e especialidades reclamados pelo País" (BRASIL, 1967)1. Para Cortez (1984, p. 11), a referida Portaria foi uma medida redentora, pois "nada havia a respeito [do estágio] até que surgiu a Port. n. 1.002, de 29 de setembro de 1967, baixada pelo Ministro do Trabalho e Previdência Social", Jarbas Passarinho.

Sustentada pela Portaria (BRASIL, 1967), muitas universidades supriam o mercado com uma mão de obra isenta das exigências trabalhistas o que, segundo Silva (1987, p. 125, 126), "favorece, na prática, a exploração dos estágios enquanto parcela do mercado de trabalho que pode ser manipulada de modo a fornecer mão-de-obra de baixo custo e fácil substituição e reposição", pois os princípios normativos da referida Portaria (BRASIL, 1967) estavam voltados às necessidades do setor empresarial que se colocava como representante legítimo da sociedade na promoção da integração universidade-sociedade.

No contexto do pós-golpe de 1964, Germano (1994), Basbaum (1977) e outros, denunciavam o envolvimento dos estudantes no mundo empresarial onde, de forma remunerada, atuavam em substituição aos profissionais da área, apesar de a ditadura militar do pós-golpe de 1964 ter neutralizado e imobilizado a luta estudantil ${ }^{2}$.

Outro documento afeto ao estágio foi a Lei n. 6.494 (BRASIL, 1977), a qual, em seu Art. $1^{\circ} \S 2^{\circ}$, diz que “os estágios devem propiciar a complementação do ensino e da aprendizagem”, isto é, o estágio era estabelecido como atividade complementar ao processo de formação.

Somente na década de 1980, por meio do Decreto n. 87.497 (BRASIL, 1982) que veio regulamentar a Lei n. 6.494 (BRASIL, 1977), foi estabelecido o caráter não complementar ao estágio na formação dos estudantes. Afirma o documento que o estágio é "atividade de aprendizagem social, profissional e cultural" e sua responsabilidade é das instituições de ensino, o que significa o reconhecimento do estágio como componente do processo de formação.

Cada um desses documentos, a seu modo e em sua época, foi útil à manutenção do status quo, contribuindo para a propagação, veiculação e difusão de ideias, valores, princípios e interesses dominantes que se sedimentaram como ideias socialmente aceitas, obscurecendo e mascarando as relações que sustentam e reproduzem as relações sociais, a sociedade de classes e a concentração de renda. Tratam todos como iguais, em uma sociedade desigual, dita homogênea, que oferece as mesmas condições para todos independente da situação econômica, etnia e credo, regida, portanto, pela neutralidade, pela justiça, e pelo amor ao próximo, ideologia presente e predominante no país desde a criação das primeiras universidades. Foi também relevante a Lei n. 5.540 (BRASIL, 1968), conhecida com LDB/1968 que, em seu Art. 20, determinava às universidades "estenderem às comunidades, as atividades de ensino e o resultado das pesquisas que lhe são inerentes". Incentivados pela LDB (BRASIL, 1968), muitos cursos passaram a desenvolver o estágio de forma articulada à extensão e, em alguns cursos, com total identidade entre estágio e extensão.

Após 26 anos da homologação do Decreto (BRASIL, 1982) que regulamentou a Lei (BRASIL, 1977), outro instrumento foi aprovado, a Lei n. 11.788 (BRASIL, 2008), que passa a ser popularmente denominada Lei do Estágio, a qual, em seu Artigo 1º afirma: "Estágio é ato educativo escolar supervisionado, desenvolvido no ambiente de trabalho, que visa à preparação para o trabalho produtivo de educandos que estejam frequentando o ensino regular em instituições de educação superior". Em seu Art. $1^{\circ} \S 1^{\circ}$ (BRASIL, 2008), informa o documento que o "estágio faz parte do projeto pedagógico do curso, além de integrar o itinerário formativo do educando", o que expressa o reconhecimento da vinculação curricular do estágio ao processo de formação. Assim, falar sobre estágio requer apreendê-lo na sua historicidade e na sua incorporação como parte do aprendizado e do projeto de formação profissional.

\section{Processo de formação dos assistentes sociais brasileiros e o paradoxo teoria-prática}

Para alguns autores, o Serviço Social teve origem na Europa, século 19, na passagem do capitalismo concorrencial ao capitalismo monopolista contando com o respaldo da Igreja Católica. Para esses profissionais essa foi a gênese do Serviço Social, base de sustentação dos primeiros cursos no Brasil, numa miscigenação de 
filantropia ${ }^{3}$ e profissionalismo, negando a tese histórico-crítica da profissão, seu movimento permeado pelo processo de desenvolvimento da sociedade capitalista, em que o surgimento e a consolidação do Serviço Social ocorreram a partir da criação e inserção do assistente social no espaço sócio-ocupacional específico. Assim, pode-se afirmar que a emergência do Serviço Social como profissão é posta no processo de compra e venda da força de trabalho, ou seja, ele se constitui profissão quando o assistente social se insere no mercado como trabalhador e passa a desempenhar funções de intervenção nas mazelas decorrentes do modo de produção capitalista ${ }^{4}$. Mas, não basta ao assistente social ter um contrato de trabalho ou estar inserido no mercado para que a profissão seja caracterizada como prática institucionalizada, afirmam Iamamoto e Carvalho (1985, p. 16); é necessário que ela responda às necessidades sociais, aquelas "derivadas da prática histórica das classes sociais na produção e reprodução dos meios de vida e de trabalho".

A história do Serviço Social brasileiro mostra que no quadro conjuntural da década de 1930, governo Vargas (1930-1945), emergiram os primeiros cursos, iniciativa do Estado varguista e segmentos dominantes da sociedade no sentido de assegurar a força de trabalho necessária à criação de um projeto nacional industrial, de caráter burguês, de expansão do modo de produção capitalista interno, com subordinação ao capital internacional. O processo de acumulação capitalista brasileiro inseria-se no polo industrial, novo mercado em consolidação no governo Vargas, com fortes vínculos ao mercado mundial. Esse foi "um momento excepcionalmente rico de significações, pela maneira como ilumina o fenômeno da instauração do capitalismo industrial no Brasil. [...] [abrange] dois períodos singulares das transformações históricas da sociedade: a vigência do sistema agrário-comercial, amplamente vinculado ao capitalismo internacional [...] e a época do sistema urbano-industrial" (IANNI, 1963, p. 18).

Assim, foram iniciadas e determinadas as condições

...o estágio congrega todo um

conjunto de ligações e rupturas

que priorizam ou relegam,

aproximam ou afastam,

fortalecem ou enfraquecem as

relações entre o mundo

acadêmico e profissional, entre

os cursos e os campos de

estágio, configurando

especificidades na participação

dos atores-sujeitos do/no

processo, com rebatimento na

formação e no exercício

profissional. concretas que tornavam a questão social mais perversa e mais visível, o que justificava a criação de cursos de Serviço Social no Brasil, iniciativa de grupos e frações da classe dominante, da igreja e do Estado. A "primeira escola brasileira [...] fundada em São Paulo em 1936, pelo Centro de Estudos e Ação Social (CEAS) [...] dava assim cumprimento a uma de suas principais finalidades: difundir e intensificar a formação e ação social católicas" (FERREIRA, apud MIGUEL, 1980, p. 20).

Em 1937, foi criada a segunda Escola de Serviço Social, no Rio de Janeiro e, nos anos seguintes, surgiram várias outras em todo o território nacional. A justificativa para a criação dessas escolas era a falta de pessoal preparado para lidar com os problemas sociais, ou seja, a necessidade de profissionais com condições de intervir nas manifestações da questão social, promovendo o ajustamento dos indivíduos, tendo em vista a manutenção da ordem e o equilíbrio na sociedade (IAMAMOTO, 1997). Mediados e defendidos pela igreja e pelo Estado, os projetos de interesse da burguesia significavam, a um só tempo, o apoio à expansão ou amadurecimento do mercado de trabalho e a difusão do sistema capitalista. Esse processo gerava mais empregos e, também, a produção da mais-valia, o aumento e a centralização do capital; em síntese, maior desigualdade e maior pauperização dos trabalhadores brasileiros. Eram projetos de cunho liberal que visavam, ideologicamente, inculcar nos trabalhadores a ideia de que eram pobres em razão da inépcia em direcionar as suas vidas. Assim, aceitavam a responsabilidade por tal situação como fracasso pessoal. O sistema capitalista deixava de ser o elemento determinante das condições de vida dos trabalhadores, bem como o responsável pelas desigualdades que imperam na sociedade. Desse modo, a condição de pobreza era assumida pelos trabalhadores em razão de (in)competência própria para se manterem e às suas famílias. Esse discurso dominante vinha e ainda hoje vem justificar o desemprego, os baixos salários, a precariedade na área de saúde, educação, moradia e outras manifestações da questão social, que decorrem da constituição estrutural do país. Segundo Netto (1992, p. 31- 32), essa transferência “supõe necessariamente que, em última instância, o destino pessoal é função do indivíduo como tal [...] tanto o êxito como o fracasso social são creditados ao sujeito individual tomado enquanto mônada social". 
Essas ideias regiam não apenas a organização da sociedade e da profissão, como ainda orientavam projetos e propostas curriculares de vários cursos superiores, compunham disciplinas e davam sustentação aos processos de formação profissional, o que pode explicar a ação do assistente social no tratamento das disfunções sociais, no ajustamento social e na reintegração social. Esse trabalho vincula-se ao Serviço Social tradicional, realizado de forma curativa, preventiva e promocional, por meio da intervenção individual, grupal e comunitária, visando assegurar o equilíbrio e a harmonia na sociedade. Por Serviço Social tradicional, segundo Netto (1981, p. 59-60), "deve-se entender a prática empiricista, reiterativa, paliativa e burocratizada que os agentes realizavam e realizam efetivamente na América-Latina. [...] que tem como parâmetro uma ética liberal-burguesa e sua teleologia consiste na correção - numa ótica claramente funcionalista - de resultados psicossociais considerados negativos ou indesejáveis". O conceito de Serviço Social tradicional, distingue-se do Serviço Social clássico, realizado pelos pioneiros e que se constitui nas fontes da profissão, a exemplo, Mary Richmond.

Somente na conjuntura de 1954, precisamente no mês de abril, que o presidente Getúlio Vargas (19511954), com a assinatura do Decreto n. 35.311 (BRASIL, 1954), regulamentou o ensino do Serviço Social em todo o território brasileiro (, 1980). Segundo Miguel (1980, p. 59), o referido Decreto (BRASIL, 1954), em "seu artigo $2^{\circ}$ define como finalidades do curso: I - promover a formação de pessoal técnico habilitado para execução [...] e direção do Serviço Social. II - aperfeiçoar e propagar os conhecimentos e técnicas relativas ao Serviço Social; III - contribuir para criar ambiente esclarecido que proporcione a solução adequada dos problemas sociais". Nessa época, tanto a formação quanto a atuação profissional, confirmavam a proposta de manutenção da ordem social num posicionamento político-ideológico que visava assegurar a coesão social segundo a ordem burguesa. De acordo com esse desiderato, eram introjetados nos indivíduos comportamentos e posturas ideais, necessárias para assegurar a normalidade social e a reprodução da força de trabalho (NETTO, 1992). O processo de formação profissional objetivava a "formação do assistente social [...] assim compreendida [...]: ‘o ensino teórico e prático, estágios supervisionados e realização de um trabalho final de exclusiva autoria do aluno"” (MIGUEL, 1980, p. 93). O estágio curricular caracterizava-se como a aprendizagem do "como fazer" por meio de instrumental técnico, sobretudo visitas, entrevistas e reuniões. O curso visava, ainda, assegurar aos futuros assistentes sociais, uma formação integral: teórica, técnica, prática e pessoal. Os estudantes eram selecionados segundo critérios pautados em aptidão pessoal, devotamento e conduta ética, compreendida como moral católica e outros critérios que viessem contribuir para o fortalecimento dessas atitudes (SETUBAL, 1983).

A busca de rompimento com o lastro conservador na profissão eclodiu no final da década de 1950 e início dos anos 1960, quando alguns assistentes sociais, na América-Latina, começaram a manifestar inquietações em relação aos propósitos ajustadores do Serviço Social, sua visão acrítica e a-histórica, ou seja, questionavam seus fundamentos teóricos, seus princípios e postulados. Com ambiguidades, contradições e incertezas, as bases da profissão foram se alterando, em um processo repleto de historicidade, marcando a profissão em seus diversos aspectos e dimensões, assegurando avanços e recuos na busca de superação de mitos e projetos conservadores. Para Setubal (1983, p. 120), foi o "despertar crítico de alguns assistentes sociais que, não satisfeitos com os resultados dos seus trabalhos, procuraram refletir sobre a sua prática, ao tempo em que se preocuparam em elaborar teorias adequadas à realidade brasileira e em questionar a metodologia até então utilizada pelo Serviço Social. O despertar desses profissionais mobilizou a classe para um movimento intitulado de "reconceitualização do Serviço Social"'.

Passar da apreensão sensível do objeto à práxis envolve um processo de maturidade profissional, o despertar da consciência para si, que leva a profissão à busca e à apreensão da realidade de forma coletiva, propondo alternativas que visassem promover mudanças na realidade em suas dimensões sociais, econômicas, políticas e culturais. Uma opção crítica dos profissionais envolve, segundo Guerra (2007, p. 8) um processo de tomada de "consciência dos fundamentos (objetivos e subjetivos) sobre os quais a prática profissional se desenvolve, porque os projetos profissionais se organizam em torno de um conjunto de conhecimentos teóricos e de saberes interventivos, de valores, princípios e diretrizes éticas e políticas, de orientação sobre o perfil de profissional que se deseja formar e de diretrizes para tal".

Do surgimento das primeiras escolas de Serviço Social ao movimento de renovação profissional, vários encaminhamentos foram aplicados ao processo de formação e, logicamente, ao estágio curricular, segundo os projetos pedagógicos dos cursos: ajustamento do homem à sociedade, intercâmbio cultural norte-americano, propostas dos segmentos dominantes e outras tendências que apresentam em suas bases componentes teórico-metodológicos conservadores. Afirma Netto (1992, p. 66): “Trata-se da relação de continuidade que efetivamente existe entre Serviço Social profissional e as formas filantrópicas e assistenciais desenvolvidas desde a emergência da sociedade burguesa. Essa relação é inegável e [...] muito complexa”. Contudo, a profissão busca se libertar de uma série de mitos que a envolve como também aos assistentes sociais. Estes mitos dizem respeito a ideias que atribuem ao Serviço Social a função de fazer a caridade, ajudar aos pobres, pois a 
sociedade é igual para todos. Aos que por si só não conseguem se manter na sociedade, passam a depender da ajuda de profissionais preparados para esse fim. Desse modo, permanece na profissão, e na sociedade em geral, ideias pré-concebidas, dentre as quais destacam-se: "a) a prática social reduzida a qualquer atividade, à atividade em geral; b) a concepção utilitária da prática social, traduzida profissionalmente na preocupação com a eficácia técnica, com o resultado imediato e visível, quantificadamente mensurável; c) a prática social apreendida na sua imediaticidade, como um dado, que teria o poder miraculoso de revelar-se a si mesma, como coisa 'natural'. Essa naturalização da vida social e essa coisificação da prática [...] são apreendidas [...] como se fossem reveladoras da concretude do real" (IAMAMOTO, 1997, p. 115).

A prática profissional regida por parâmetros instrumentais, pelo ativismo e pelo imediatismo, apresenta a imagem ilusória de uma profissão que intervém na questão social, traduzindo em eficiência e eficácia a atuação profissional junto às relações capital e trabalho. Muitas vezes tal avaliação ocorre por meio de relatórios e dados estatísticos que explicitam a dita eficiência e eficácia, condição exigida por muitas instituições empregadoras e campos de estágio. São dados que justificam a razão de ser da própria instituição e revelam uma pseudo-eficiência de uma intervenção profissional, resultado do trabalho transformador do assistente social. Assim, subjugada por teorias conservadoras e envolvida por mitos e ideologias, a prática profissional, em muitos espaços, tem se mantido ingênua, posição que reforça a dicotomia teoria-prática, ao canonizar os profissionais que vivem o dia-a-dia da prática, cabendo à formação profissional o desenvolvimento de teorias no espaço da intelectualidade, a academia.

\section{Estágio no processo de formação do assistente social}

O processo de renovação do Serviço Social brasileiro trouxe outro posicionamento teórico-político à profissão, devido a sua vinculação à vertente marxista, conforme orientação da XXI Convenção da ABESS, em 1979, quando foi aprovado um novo currículo mínimo para o Curso de Serviço Social. Este indicou novos rumos para o processo de formação, trazendo uma leitura e intervenção crítica na realidade brasileira. O editorial da Revista Serviço Social e Sociedade (1984, p. 3) mostra que a busca de rompimento com a base teórica conservadora da profissão e a reformulação do seu processo de "formação profissional vem se constituindo em preocupação central da categoria [...]. A Convenção da Associação Brasileira de Ensino de Serviço Social, realizada em Piracicaba, definiu como um dos compromissos a serem assumidos pelas Entidades profissionais e seus agentes, a necessidade de revisão do Currículo Mínimo do Curso de Serviço Social. [...] em 1979 [...] o novo Currículo Mínimo é aprovado pelos convencionais presentes em meio a um animado debate". A viabilização desse encaminhamento da Convenção da ABESS resultou, processualmente, em novos projetos pedagógicos nas escolas de Serviço Social que, rompendo com o quadro teórico conservador, buscavam articulação com o movimento popular e com a luta dos trabalhadores. A partir de então, muitas escolas discutiam/trabalhavam o processo/projeto de formação profissional, com base nas suas contradições e no contexto da luta de classes, posicionando-se a favor dos trabalhadores, visando uma sociedade justa, democrática, fraterna e solidária (UCG/SER, 1985). Contudo, essa não foi uma retomada unânime na profissão que passou a conviver com as duas posições, mesclando tanto a formação quanto o exercício profissional com teorias críticas e conservadoras. Logicamente, essa realidade manifestou-se também nos estágios, em que a cisão teoria-prática se fazia presente, fortalecendo o conhecido refrão de que "na prática a teoria é outra" .

Em meio à dicotomia e paradoxos na concepção e relação teoria-prática no Serviço Social, e com as alterações societárias decorrentes do golpe de 1964, os projetos e experiências profissionais e de estágio mais comprometidas com os segmentos populares e de trabalhadores foram, em nome do nacionaldesenvolvimentismo, desarticulados e/ou trocados por trabalhos e programas assistencialistas vinculados à Política Social do Governo. Assim, os movimentos comunitários, rurais e urbanas, os movimentos sociais de base em diversas áreas, o movimento estudantil, as organizações de trabalhadores, os sindicatos, foram desmantelados. Muitos desses programas se voltaram aos segmentos da classe dominante, ampliando a atuação dos órgãos governamentais na área social. Em âmbito local e nacional, era priorizado o estágio curricular em instituições indicadas pelo sistema, nos recém-criados programas governamentais e de extensão, dentre eles, o Projeto Rondon, Projeto Mauá, Projeto de Picos, no Piauí, entre outros.

Dado ao contexto da ditadura militar, alguns campos de estágio foram absorvidos por programas comunitários da Igreja Católica, tal qual ocorreu em Goiânia, atendendo a solicitações de vigários e leigos engajados em movimentos sociais, sob a afirmativa de que o trabalho comunitário da instituição oferecia formação mais adequada aos estagiários, ao envolver os três processos de atuação à época, final dos anos 1960 e década de 1970: Caso, Grupo e Comunidade. Muitos desses trabalhos eram desenvolvidos nas Comunidades Eclesiais de Base, com o desenvolvimento da teologia da libertação, importante posicionamento 
de um segmento da igreja católica que se voltava para os desafios da realidade social da América Latina, nos aspectos relacionados à terra, moradia, saúde, educação e a outros que se agravavam com a questão social posta pelo modo de produção capitalista. Por outro lado, é possível verificar a subjugação, ainda na década de 1970, dos assistentes sociais à Igreja Católica, com a disponibilização de mão-de-obra semiqualificada e supervisionada dos estagiários, sem qualquer ônus.

Também o Estado apresentava crescimento significativo no número de vagas para estagiários, fato que teve relação não só com a criação da Secretaria de Serviços Sociais, indicada e assumida como novo campo de estágio, como também com o incentivo dos governos populistas e militares aos programas de política social (MIGUEL, 1980). Assim, verifica-se um retrocesso ético-político e teórico-metodológico no Serviço Social que, para atender ao novo sistema, volta a muitas práticas assistencialistas já superadas.

Somente na década de 1980 o país retoma seu processo democrático e uma nova Constituição (BRASIL, 1988) é homologada, a denominada Constituição Cidadã. No âmbito da formação profissional, em 1996 a Associação Brasileira de Ensino em Serviço Social (ABESS), hoje Associação Brasileira de Ensino e Pesquisa em Serviço Social (ABEPSS), apresenta as Diretrizes Curriculares (ABESS, 1996) para os cursos de Serviço Social, em todo o Brasil. Até os dias atuais, elas orientam os projetos curriculares e informam que estágio é "uma atividade curricular obrigatória que se configura a partir da inserção do aluno no espaço sócio-institucional objetivando capacitá-lo para o exercício do trabalho profissional, o que pressupõe supervisão sistemática. Esta supervisão será feita pelo professor supervisor e pelo profissional do campo, através da reflexão, acompanhamento e sistematização com base em planos de estágio, elaborados em conjunto entre Unidade de Ensino e Unidade Campo de Estágio, tendo como referência a Lei 8662/93 (Lei de Regulamentação da Profissão) e o Código de Ética do Profissional (1993). O Estágio Supervisionado é concomitante ao período letivo escolar" (ABESS, 1996, p. 19). O estágio deverá possibilitar, ao estudante, o desenvolvimento de habilidades, atitudes e principalmente valores que, somados a contatos com projetos e propostas de trabalho, estudos e pesquisas, vão compondo o processo de formação e fortalecendo o projeto ético-político-profissional. Apesar de ele ter uma orientação comum, voltada para todas as áreas e em todo o território nacional, sua condução assume características próprias e específicas em cada curso, e até no interior de um mesmo curso, comprovando que sua apreensão e seu desenvolvimento não são únicos e homogêneos. Cada projeto curricular tem a sua organização própria e, os supervisores adotam metodologias, muitas vezes, divergentes entre si.

Com base nessa realidade e como parte do esforço de regulamentar o exercício profissional da supervisão de estágio, em 2008, o Conselho Federal de Serviço Social, por meio da Resolução n. 533 (CFESS, 2008), confirma o conceito de estágio expresso nas Diretrizes Curriculares (ABESS, 1996) e, em 2010, a ABEPSS aprova a Política Nacional de Estágio (PNE) (ABEPSS, 2009), que diz: “as UFAs [Unidades de Formação Acadêmicas] e seus sujeitos não podem furtar-se da contribuição na qualificação e aprofundamento dos debates, proposições e práticas para a efetivação do papel do estágio [...] em consonância com as Diretrizes Curriculares e com a direção ético-política do Serviço Social brasileiro" (ABEPSS, 2009, p. 1). A PNE estabelece normas para que o estágio fortaleça um projeto de sociedade e de profissão que concorra para ampliar direitos, pavimentando a direção da emancipação humana. Isso se dá na contramão da realidade sócio econômica desigual de grande expansão e adensamento, no contexto do modo de produção capitalista, em escala mundial. Ressalta-se que o aprofundamento da desigualdade também ocorre em decorrência do crescimento de ajustes fiscais, estratégias capitalistas de enfrentamento das suas crises, que resultam, entre outros, em focalização e redução de políticas públicas, implicando em crescente distanciamento da oferta de políticas universais, que superem a seletividade e garantam acesso igualitário, pela via do Estado. A Política Nacional de Estágio ratifica a natureza do estágio expressa na Lei 11.788 (BRASIL, 2008) e confirma que o estágio poderá ser obrigatório ou não-obrigatório, de acordo com o projeto pedagógico dos cursos. Assim, ele foi se revestindo de significado legal, em âmbito nacional e profissional. Contudo, o estágio não pode ser considerado um elemento independente, isolado da realidade e do projeto curricular do curso, pois, teoria e prática são como faces diferentes de uma mesma moeda, portanto constituintes da proposta de estágio do Serviço Social. Segundo Kameyama (1989, p. 101), teoria e prática são "inseparáveis no processo do conhecimento e devem ser consideradas na sua unidade, levando em conta que a teoria não só se nutre na prática social e histórica como também representa uma força transformadora que indica à prática os caminhos da transformação".

A qualidade dada ao estágio, em seu desenvolvimento, depende, em grande parte, do conhecimento da proposta curricular por parte dos supervisores, acadêmicos e de campo, e da articulação entre eles. Essa articulação viria assegurar e possibilitar a troca de conhecimentos e experiências e maior articulação teoriaprática. Nesta direção, Martinelli (1995, p. 68-69) ressalta que, se:

"pensarmos que o estágio, por si só, tem o poder de articular a teoria à prática, somos candidatos a uma eterna frustração. O estágio não poderá unir aquilo que está desunido na prática. O estágio não poderá ser 
elemento de conexão do que não está conectado enquanto concepção. Portanto, trabalhar a questão da relação teoria-prática é, fundamentalmente, assumir que as práticas sociais são socialmente determinadas. A identidade dessas práticas não se marca pela reprodução do já produzido, mas, exatamente ao contrário, são práticas que se marcam pela determinação do novo”.

Desse modo, o estágio congrega todo um conjunto de ligações e rupturas que priorizam ou relegam, aproximam ou afastam, fortalecem ou enfraquecem as relações entre o mundo acadêmico e profissional, entre os cursos e os campos de estágio, configurando especificidades na participação dos atores-sujeitos do/no processo, com rebatimento na formação e no exercício profissional.

\section{Algumas considerações}

O contexto de crise e a estratégia de ajuste fiscal em curso impactam ainda mais a distribuição da riqueza socialmente construída, o que amplia as já tão perversas e profundas manifestações da questão social, situação que confronta com o significado e as lutas históricas do Serviço Social na sociedade burguesa e também com as sucessivas investidas de ruptura com o conservadorismo. Paradoxalmente, ocorre a sua reprodução. Por isso, o enfrentamento do conservadorismo no interior da profissão é um processo e um movimento que requerem uma reflexão contínua, discernimento coletivo e compromisso com o fortalecimento de um projeto de profissão que se vincule, necessariamente, às lutas e demandas históricas da classe trabalhadora.

Nas sociedades de ordem burguesa, o capitalismo e suas crises estruturais têm gerado a precarização crescente das condições de trabalho e de vida das pessoas, determinando, e ao mesmo tempo ocultando, que essa condição é decorrente da lógica de (re)produção da chamada questão social. Tal dinâmica deixa marcas tanto na concentração da riqueza, que se eleva, quanto na expansão da pobreza, pois as perversas condições do modo de produção capitalista impedem que, por meio do trabalho, a realidade de vida dos trabalhadores alcance outro patamar, à medida que a acumulação do capital é proporcional à acumulação da miséria.

Pode-se afirmar que a realidade envolta ao estágio vai além do processo de formação, pois abrange a realidade socioeconômica, as condições de vida e de trabalho da classe trabalhadora, a relação com o mercado e o meio profissional, locus de trabalho dos profissionais e do desenvolvimento do estágio. Essa realidade deve contribuir para que o estudante possa vivenciar, por meio do estágio, o projeto ético-político-profissional do Serviço Social brasileiro em sua perspectiva crítica e compromisso coletivo, tanto na dimensão interventiva quanto investigativa, considerando que o Serviço Social é uma profissão comprometida com um projeto societário de emancipação humana, decorrente da igualdade e da liberdade. Desse modo, o estágio como componente do processo de formação deverá se realizar com qualidade e coerência com o projeto de sociedade e de profissão, sustentando-se no compromisso ético-político-profissional de superação do conservadorismo burguês e de construção da hegemonia dos interesses populares.

\section{Referências}

ASSOCIAÇÃO BRASILEIRA DE ENSINO EM SERVIÇO SOCIAL (ABESS). Diretrizes gerais para o Curso de Serviço Social (com base no currículo mínimo aprovado em Assembleia Geral Extraordinária de 8 de nov. de 1996). Disponível em: http://www.abepss.org.br/ files/Lei_de_Diretrizes_Curriculares_1996. Acesso em: abr. 1997.

ASSOCIAÇÃO BRASILEIRA DE ENSINO E PESQUISA EM SERVIÇO SOCIAL (ABEPSS). Ensino da prática profissional no Serviço Social: subsídios para uma reflexão. Diretrizes Curriculares: polêmicas e perspectivas. TEMPORALIS. Brasília, ano I, n. 2, dez. 2000, p. 153.

Política Nacional de Estágio (PNE). Documento Base. ABEPSS, 2009.

BASBAUM, L. História sincera da República: (1961 a 1967). São Paulo: Alfa-Omega, 1977.

BRASIL. Lei $n^{\circ}$ 11.788. Dispõe sobre o estágio de estudantes e dá outras providências. 25 de Setembro de 2008.

Constituição da República Federativa do Brasil. Promulgada em 05 de outubro de 1988.

Presidência da República. Decreto no 87.497 de 19 de agosto de 1982. Regulamenta a Lei no 6.494 de 7 de dezembro de 1977, que dispõe sobre o estágio de estudantes de estabelecimento de ensino superior e de ensino profissionalizante e do segundo grau regular e supletivo, nos limites que especifica e dá outras providências. Diário Oficial [da] República Federativa do Brasil. Brasília, 19 ago. 1982.

Presidência da República. Lei no 6.494, de 7 de dezembro de 1977. Dispõe sobre os estágios de estudantes de estabelecimento de ensino superior e de ensino profissionalizante de segundo Grau e Supletivo e dá outras providências. Diário Oficial [da] República Federativa do Brasil. Brasília, 9 dez. 1977. 
Congresso Nacional. Lei n ${ }^{\circ} 5.540$, de 28 de novembro de 1968. Fixa normas de organização e funcionamento do ensino superior e sua articulação com a escola média e dá outras providências. Diário Oficial [da] República Federativa do Brasil. Brasília, 29 nov. 1968.

Ministério do Trabalho e Previdência Social. Portaria no 1.002 de 29 de setembro de 1967. Dispõe sobre admissão de estagiários nas empresas. Brasília. Diário Oficial [da] Republica Federativa do Brasil. Brasília, 6 out. 1967.

. Decreto ${ }^{\circ}$ 35.311. Regulamenta a Lei n. 1889, de 13 de junho de 1953 que Dispõe sobre os objetivos do ensino do Serviço Social, sua estruturação e ainda as prerrogativas dos portadores de diplomas de Assistentes Sociais e Agentes Sociais. Brasília, 2 de Abril de 1954.

CORTEZ, J. C. O estágio de estudantes na empresa: comentários à Lei n. 6.494, de 07.12.1977 e ao Decreto n. 87.497, de 18.08.1982. São Paulo: LTr, 1984.

FERREIRA, O. C. Resumo das origens do Serviço Social no Brasil, focalizando a interferência do pensamento católico. Arquivo da Pontifícia Universidade Católica de São Paulo, 1959. In: MIGUEL, W. L. O Serviço Social e a promoção do homem: um estudo de ideologia. Goiânia: Editora UCG, 1980.

FIORI, J. L. O voo da coruja. Rio de Janeiro: Record, 2003.

GERMANO, J. W. Estado militar e educação no Brasil. São Paulo: Cortez, 1994.

GUERRA, Y. O projeto profissional crítico: estratégia de enfrentamento das condições contemporâneas da prática profissional. Serviço Social e Sociedade, São Paulo, ano XXVIII, n. 91, p. 5 a 33, mar./2007.

. Ensino da prática profissional no Serviço Social: subsídios para uma reflexão. Diretrizes Curriculares: polêmicas e perspectivas. TEMPORALIS. Brasília, ano I, n. 2, p. 153, jul. a dez./2000.

IAMAMOTO, M. Renovação e conservadorismo no Serviço Social. São Paulo: Cortez, 1997.

IAMAMOTO, M; CARVALHO, R. Relações sociais e Serviço Social no Brasil. São Paulo: Cortez, [Lima, Peru], 1985.

IANNI, O. Industrialização e desenvolvimento social no Brasil. Rio de Janeiro: Civilização Brasileira, 1963.

KAMEYAMA, N. Metodologia: uma questão em questão: concepção de teoria e metodologia. Cadernos ABESS. São Paulo, n. 03, p. 99. Março 1989.

MARTINELLI, M. L. Serviço Social: identidade e alienação. São Paulo: Cortez, 1995.

NETTO. J. P. Capitalismo monopolista e Serviço Social. São Paulo: Cortez, 1992.

. A crítica conservadora à reconceptualização. Serviço Social e Sociedade. São Paulo, p. 59, 1981.

SERVIÇO SOCIAL E SOCIEDADE. Editorial. São Paulo, ano V, n. 14, abr. 1984.

SETUBAL, A. A. Alguns aspectos da história do Serviço Social no Brasil. Serviço Social e Sociedade. São Paulo, ano IV, n. 12, ago. 1983. SILVA, A. A. da. A questão dos estágios e o mercado de trabalho. Serviço Social e Sociedade São Paulo, ano VIII, n. 24, p. 124, ago. 1987. UNIVERSIDADE CATÓLICA DE GOIÁS, Departamento de Serviço Social. Projeto Pedagógico, Goiânia, 1985.

\section{Notas}

1 A busca do desenvolvimento teve início com o projeto de industrialização consolidado no primeiro governo de Vargas, a partir de 1930, e veio a se constituir na “coluna vertebral do 'desenvolvimentismo' brasileiro”. Adquiriu maior consistência no final do segundo governo Vargas (19511954), prorrogando-se no período 1955-1960, com o "desenvolvimentismo internacionalizante de [Juscelino Kubitschek] que se estende, de forma conservadora e autoritária, durante o regime militar, em particular na gestão do general Geisel” (FIORI, 2003, p. 11-12).

2 Com medidas autoritárias e repressivas, violência, torturas, perseguições, cassações de direitos civis, suspensão de partidos políticos, condenação de grandes expoentes intelectuais ao exílio, dentre outras, o sistema militar se fortalecia. Segundo Basbaum (1977, p. 169), instalava-se o terror cultural cujo modelo guardava grande semelhança ao protótipo alemão-o “fascismo, [...] [que] é, antes de tudo, a supremacia da força bruta contra a inteligência". Nesse sentido, afirma Germano (1994, p. 29), o nazi-fascismo é uma "forma de totalitarismo [...] vincula[da] a um determinado nível do desenvolvimento do capitalismo".

3 Para a igreja católica, a filantropia justificava-se, pois a questão social, antes de ser uma questão econômico-política, era considerada uma questão moral e religiosa.

4 Netto (1992, p. 69) pondera que a concretização, de fato, da ruptura do Serviço Social com suas protoformas somente ocorreu com a inserção do profissional no mercado de trabalho, por meio de relações de assalariamento, para intervir nas expressões da questão social com parâmetros profissionais: “É com esse giro que o Serviço Social se constitui como profissão, inserindo-se no mercado de trabalho [...] tornando-se vendedor de sua força de trabalho. [...] Não é a continuidade evolutiva das protoformas ao Serviço Social que esclarece a sua profissionalização, e sim a ruptura com elas".

5 Segundo Guerra (2000, p. 153), essa afirmativa refere-se à posição e ao espaço que o “ensino da prática tem ocupado [...], secundário no âmbito do currículo. Aqui está uma clara subalternidade das 'chamadas' disciplinas 'práticas' em relação às ‘teóricas'. Historicamente, no Serviço Social, o ensino da prática tem sido limitado: 1) ao ensino de instrumentos e técnicas e/ou das 'chamadas' metodologias de ação; 2) ao aprendizado restrito aos campos de estágio". 


\section{Maisa Miralva da Silva}

maisasilva@uol.com.br

Doutora em Política Social pela Universidade de Brasilia (UNB)

Professora de Serviço Social na Pontifícia Universidade Católica de Goiás (PUC-GO)

\section{Eleusa Bilemjian Ribeiro}

eleusaribeiro_2@hotmail.com

Doutora em Serviço Social pela Universidade Federal do Rio de Janeiro (UFRJ)

Professora de Serviço Social na Pontifícia Universidade Católica de Goiás (PUC-GO)

\section{PUC-GO}

Av. Universitária, 1069, Setor Universitário

Goiânia - Goiás - Brasil

CEP: 74605-010 